\title{
Are we going for greener Products?
}

\author{
Der Fokus von Forschungen zur Integrierten \\ Produktpolitik lag bisher vor allem auf den \\ Möglichkeiten der Einflussnahme: Welche In- \\ strumente führen zu einer Verbesserung ent- \\ lang des gesamten Lebensweges? Ob der \\ Ansatz der Integrierten Produktpolitik wirklich \\ erfolgreich ist, wurde dagegen bisher kaum \\ untersucht.

\section{Von Christian Poll und Frieder Rubik}

ntegrated Product Policy (IPP) has been developed nationally since the early $1990 \mathrm{~s}$. But while ideas for developing tools, methods and activities have been numerous, nobody has yet come up with ways to monitor the effects of implementing IPP measures. As a result, IPP currently builds on the belief that bringing greener products to the market, and increasing the pull on such products, will actually decrease environmental impacts from products in general.

The European Commission elaborated a Green Paper and later a Communication on IPP (1). They form the strategic basis for a study carried out for the European Commission. Objectives of this study were to reveal retrospectively the landscape of indicators for the European IPP and to set a prospective framework for working with indicators for IPP. The report has been prepared by the Institute for Product Development, the Centre for Alternative Society Analysis and the Institute for Ecological Economy Research (IÖW) (Poll 2006). Though we are in „virgin territory“, the aim is to encircle a group or Basket of indicators, which - if followed over time - can express the environmental progress of products due to IPP measures.

\section{Indicators}

Indicators are variables, selected to present a complex reality in a condensed form. Thus, indicators are developed with specific purposes and with their own criteria and quality requirements. The European Environmental Agency has developed criteria for good indicators (EEA w.y.). Namely, policy relevance and the progress toward targets, available and routinely collected data, appropriate space and temporal coverage, a national scale, representative data, understandable and methodologically well founded data, topics covered in CSI and priorities, timeliness, and good documentation. A useful approach applied in our research is the DPSIR framework (Gabrielsen 2003). DPSIR stands for Driving forces - Pressures - State - Impact - Responses. The DPSIR framework was meant to help with understanding and monitoring the political agenda, although it is primarily suitable for classical regulation measures. It not only comprises the cycle of D-P-S-I-R, but also combinations of these five elements. Such examples and the core DPSIR cycle are presented in Figure 1

\section{DPSIR related to IPP}

The overall objective of IPP is to lower the impact products have on the environment. This means that we interpret IPP as a toolbox of responses, which aim at creating changes in driving forces in the European market-based society, to lower pressure on the environment.

IPP is a complex concept. So, whereas the DPSIR model may seem simple and feasible for environmental indicators in general, experience with cleaner products projects over the years reveals the following obstacles:

- An effect is not always traceable back to only one project, but rather to a group of projects.

- Effects in driving forces (for example changes in production) are often considerably delayed from the project implementation phase.

- Effects in pressures (for example decreased emissions of a chemical) are often even further delayed.

- Effects in state (for example the population of fish in a river)

Figure 1: Indicators and information linking DPSIR elements

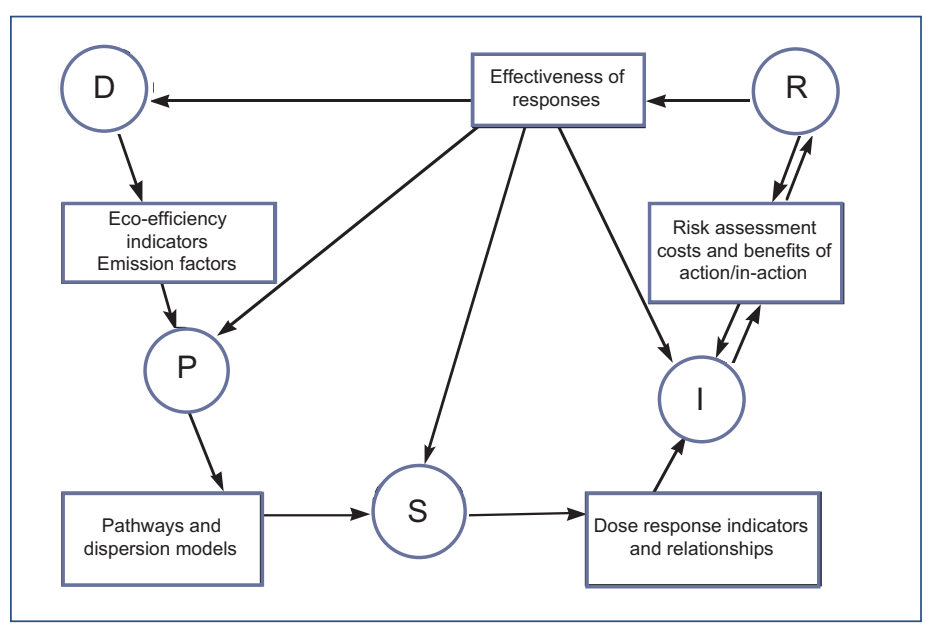

Source: Gabrielsen 2003 
or impact (bathing conditions in a lake) often appear after several years, and with many more noise factors from the lake surroundings.

1 A change in response from an actor is very difficult to relate directly to one project or one other response. Rather, an actor's behaviour depends on numerous inputs from daily life, such as other legislation, market opportunities, threats, media focus, public opinion and personal life.

Several attempts have been made, especially in eco-labelling fora, to monitor the development or success of an IPP activity. The purpose of such studies is to monitor the dissemination of an activity on the market. This is the first prerequisite for success of an IPP activity. Such studies are, however, solely related to responses in the DPSIR terminology, that is to monitor the success of the response of "putting eco-labels on the scene“. There is no connection to change in driving forces until such change is specified, described and monitored.

\section{Present IPP indicators and sources}

Our research reveals that there are no obvious indicators, which can be selected and used directly. Most indicators are either pure response indicators, measuring the success of an instrument without covering the changes generated by the instrument, or they are classical environmental pressure or state indicators. A few cover broader aspects, such as the consumption index, but they are aggregated and complex figures to work with, and combine the other indicators into a more aggregated level.

If one considers sustainable development indicators, an overview shows that there is a fairly large range of indicator types according to the DPSIR approach. Characteristic for the policy efficiency indicators is, that they only measure the degree of visible success of the policy itself, by for example the number of licenses for the EU Flower. They do not provide a measure of decreased environmental impact from a product group, as a result of the EU Flower.

There is, in general, no attempt in these indicators to assess the changed environmental impact as a result of the activity. Such an attempt should consider direct and indirect effects and is confronted with a complicated impact chain encompassing a series of influencing factors which might be difficult to isolate and separate. In such studies, the mapping of the average market product is especially problematic. Is it a European produced, or a Far-East produced product? One study has attempted to quantify the link from R to D and P (Cadman 2004). Here, a systematic attempt is presented, in which the difference in environmental impact from an eco-labelled product compared with the market average product is estimated. A scenario-based assessment is made of potential direct environmental benefits, due to a certain penetration of markets with eco-labelled products, thereby establishing some kind of link from R-to-D-to-P. However, the approach does not reveal anything about changes in D, so the DPSIR coverage is more like a short-cut from R-to-P.

\section{Coupling the indicators to the DPSIR model}

A much aggregated indicator type is the kind of national Life cycle assessment (LCA) or mass flow analysis supplied with impact categories such as the „Environmental impact from Swedish consumption per citizen per year". The principle is similar to the footprint work, but much more complex. In the DPSIR perspective, such indicators cover the whole D-P-S-I section of the model, but do not reveal mechanisms about $\mathrm{D}$ nor the relationship back to $\mathrm{R}$.

The classical environmental indicators for emissions, mainly on pressures, are also relevant, especially if they can be converted from production unit to product unit as a reference point. This task is about allocating activities and input in the factory to output in the form of products; and, doing so in the product chain, adding up the contributions to the end products. This task is very well established in business where economic aspects are concerned, because cost accounting must allocate input costs to cost per unit and sales price.

This task will become more feasible as IPP activities emerge. If many companies work in a way that is product-oriented and document and publish information, then data will be available in the product chain - both for aggregation purposes, and at any sub-level of the product chain.

Concluding, we have determined two distinct worlds of indicators for IPP:

- One world is around responses. It informs about political processes, activities and agreed or implemented measures and instruments. These indicators measure the visible reaction to one or more IPP measures. Apparently, these indicators are response effectiveness indicators. A more precise name would be response dissemination indicators. See Figure 2, as they make no link to $\mathrm{D}$.

- The other world of indicators are typically very scientifically based methodologies for impact assessment, deriving often

Figure 2: Indicator's coverage of the DPSIR in relation to IPP

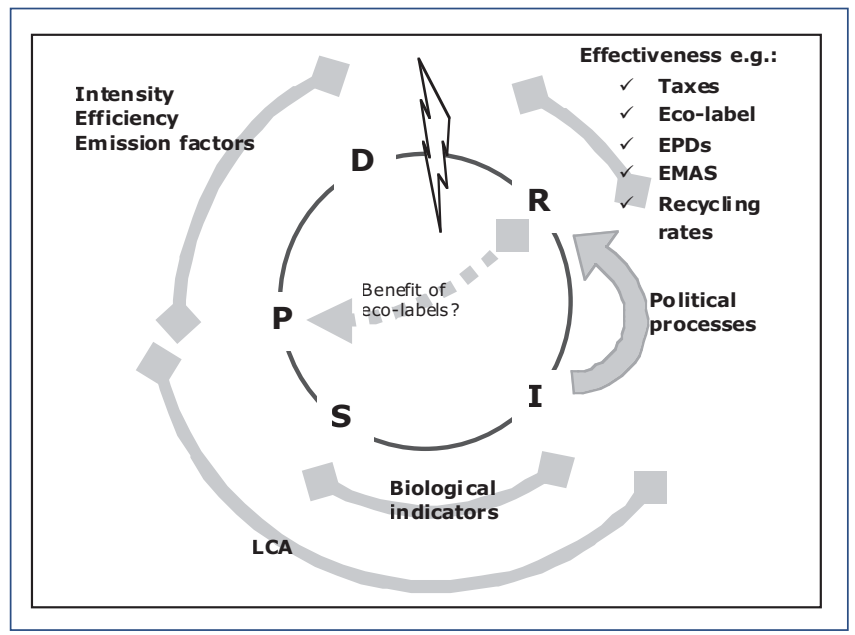

Source: Poll 2006 
from the LCA community or biological sciences which can take us from pressures over state to impact.

Thus, there is a strong need for defining indicators, which can connect the two worlds, especially over the R-to-D border, because the I-to- $\mathrm{R}$ border is about decision support to the political process.

\section{Organisational behaviour - the missing link}

Our survey has revealed a missing link in the causality chain that connects an IPP activity with a measurable environmental effect. This area has not been investigated thoroughly (Füssl 2002). At the moment, many companies think that they have made great efforts by introducing an environmental management system and believe they have now finished the task. The focus may be moving away from environmental issues to corporate social responsibility (CSR). The huge challenge for CSR strategies is to develop a truly integrated strategy with benchmarking on key parameters.

An additional problem is that most environmental efforts by companies have focused around the classical technical company environmental specialist, working in the Health, Safety and Environment Department. However, a number of IPP tools will target other departments in the company, for example marketing, the sales or product manager, the product developers or top management.

The axe, which cuts the DPSIR cycle in two, is knowledge about how companies react to external changes generated by typical IPP measures. In this grey zone, we find theories and empirical findings from economics, organisation theories, behaviour models and even psychological aspects. If revealed, such knowledge will help us to establish the link to understanding and modelling changes in driving forces and pressures resulting from specific IPP responses. If this knowledge became detailed, we could define indicators, which could guide us in the selection of the most effective IPP tool for a given situation. This might be a combination of product group, stakeholder and legislative surroundings.

\section{Alternative sources of indicators}

Apart from the area of standardisation, very few sources are obvious when searching for indicators for IPP. However, ongoing development in European legislation, such as REACH, EuP, Cardiff, Lisbon, ETAP, WEEE, procurement rules and others may provide new frameworks that may foster useful indicators for IPP.

The intention of IPP is to influence and green the markets. But how does IPP work? Have its measures and instruments any impact? Does it contribute to lower environmental burdens? As one answer to these questions, the idea of a Basket-of-products arose. Its approach reduces and compresses a complex and multi-dimensional amount of information into a few indicators describing even fewer product groups. The Basket-of-products idea in the context of IPP would naturally follow an economic and environmental pathway and should possess the following features:

I development of the environmental features of a representative bundle of products over time,

I highly-aggregated indicators clarifying state and development, that are easy to understand and reproduce,

I indications of the success and failures of an IPP.

Establishing the Basket needs the selection of product groups and of indicators. The selection of product groups could follow two alternative approaches, namely:

I Representative selection of products groups or

- Environmental prior ones.

The first approach is oriented towards the economy. It intends to represent it and to give an overall picture of its present state. The second approach is based on the environmental relevance of product groups. We followed the second approach ba-
Figure 3: The basket of products and the DIPSIR-model

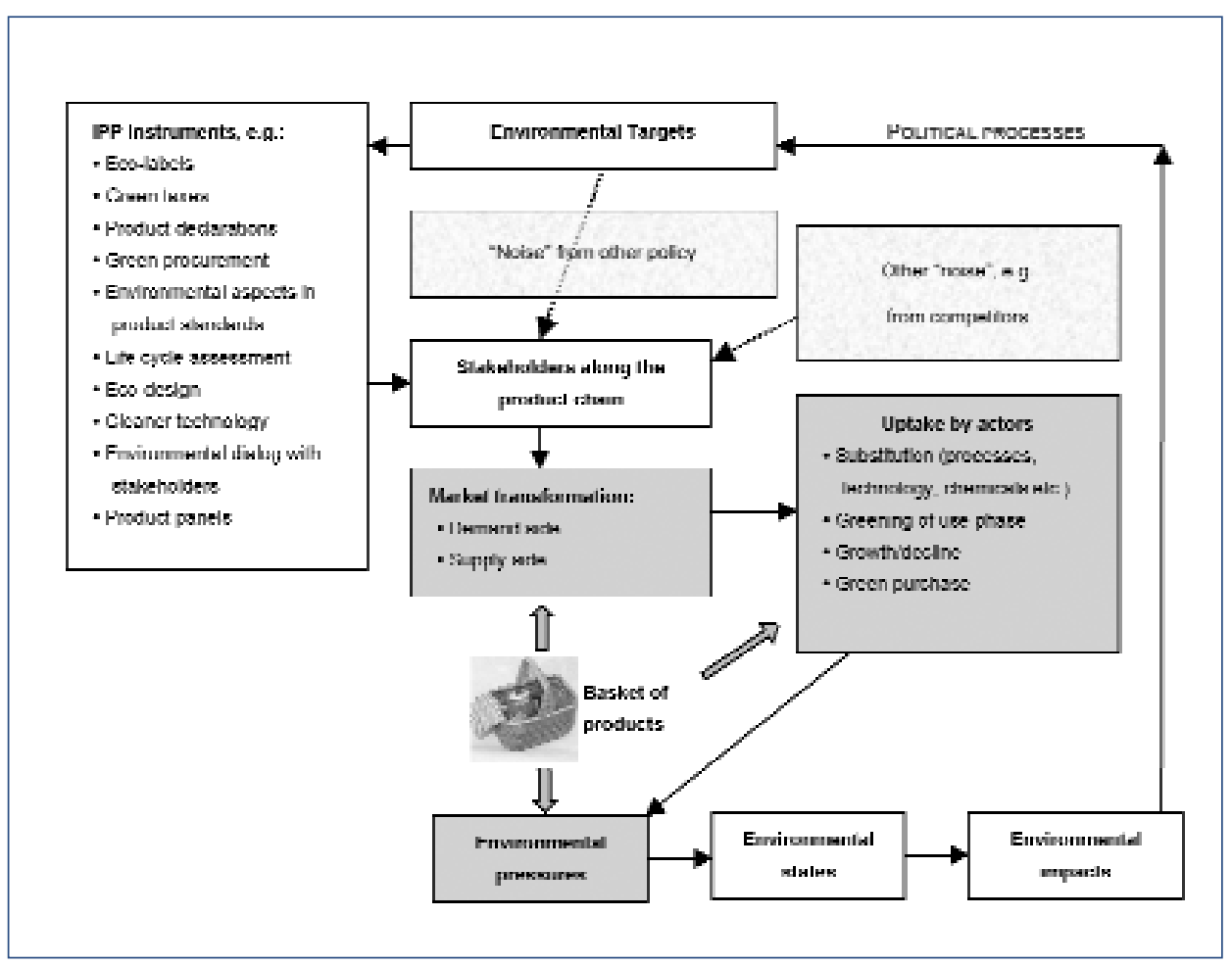

Source: Poll 2006 
sed on the goal of IPP to reduce environmental burdens deriving from products. Environmental relevance is one requirement for the selection of appropriate product groups. Additionally, we took into account:

- Potential for improvement, including the environmental span of products on the market;

- Steerability of IPP tools to produce relevant changes to environmental features;

- Availability of data with a longer time series.

Indicators representing a product group have to fulfil a series of more general requirements mentioned above as criteria for good indicators. Other relevant aspects are:

- The indicators should reflect environmental improvements along the product's life cycle.

- Indicators must reflect different kinds of environmental impacts, for example energy consumption, transportation and land use.

I Indicators should cover the whole set of IPP tools.

- Indicators should preferably cover the R-D-P part of the DPSIR cycle.

Based on these considerations and requirements, we propo-

se an outline of the Basket-of-products oriented towards

- a green market transformation,

- its uptake by actors and

- pressures due to products. The IPP Basket of products has some restrictions:

- Market transformation: The IPP Basket-of-products may report on the state and changes of the products and their transformation over time. The basket does not give any detailed insight into the dynamics of the market transformation nor into the reasons why products change. Therefore, some supporting indicators may add such knowledge.

- Uptake: The uptake by actors is reported only partly in the proposed IPP-basket. The selective growth and decline - that is the pure quantitative market effects - of products will not be reported by the Basket. This challenge could be met by also indicating production and/or sales numbers.

- Environmental pressures: The environmental pressures due to products are based on their environmental features, as reported by the selected indicators. As mentioned, the indicators concentrate on the most relevant aspects and do not stress all the plethora of different emissions linked to products.

Altogether, we selected 25 different product groups, namely air conditioning systems, cars, coloured books, desktop computers, dolls, domestic armchairs, kitchen cleaning agents, kitchen tissue paper, lawnmowers (petrol), light bulbs, men's leather shoes, mobile phones, office printers, paint (indoor and outdoor), pork, refrigerators, polyester shirts, small circulation pumps, textile cleaning agents, cotton T-shirts, TVs (28“), washing machines, wheat bread and windows for houses. For each product group, we identified between 3 and 5 indicators. Table 1 presents some sample indicators proposed for four product groups.
In total, we selected 69 indicators for the 25 products in the Basket, predominantly pressure indicators. A number of aspects are common to several product groups. For example, energy consumption will be relevant to any energy-using product.

The pressure indicators are supplemented with some supporting response indicators. These are mainly policy-effectiveness indicators - that is indicators for responses according to the DSPIR model - which were selected due to ease of monitoring:

- number of type I eco-labelling licenses;

- number of EPD registrations according to the coming ISO 14025;

- number of products sold from certified organic agriculture;

- number of EMAS registrations and the number of ISO 14001 certified companies;

- uptake of the ISO series 14040-48 as an indication of application of life-cycle approaches, of the ISO TR 14062 as an indication of the uptake of eco-design, and a number of sectorspecific standards (for example the coming ISO 21929 Sustainability in building construction - sustainability indicators);

- number of comments to Technical Committees of CEN.

The point in maintaining both the Basket and the supporting indicators is that there may be some synergy to be used in both directions. Establishing an overall rate would need a double weighting:

-Weighting per product group: 25 product indexes would require a weighting method for weighting the aspects each indicator covers against each other. Such methods are inherent components of LCA methodologies, but they relate to welldefined environmental impact categories, which form the backbone of such methodology. LCA weights in two stages: the normalisation and the weighting.

- Weighting across product groups: As a theoretical second

Table 1: Some suggested indicators for the selected product groups for the Basket of products

\begin{tabular}{|c|c|}
\hline Product group & Indicators \\
\hline $\begin{array}{l}\text { Windows for houses } \\
\text { (wood) }\end{array}$ & $\begin{array}{l}\text { Insulation factor of window ( } U \text { value) } \\
\text { Fraction of windows on the market without } \\
\text { chromium, copper and arsenic used for the preserva- } \\
\text { tion of the wood frame } \\
\text { Fraction of windows made of FSC-certified wood }\end{array}$ \\
\hline Cotton T-shirts & $\begin{array}{l}\text { Pesticide residue content in the cotton oil, used } \\
\text { locally by the cotton field workers (measured directly } \\
\text { in the oil or indirectly in breast milk of the women in } \\
\text { the area). } \\
\text { Formaldehyde content in clothes. } \\
\text { Energy use in production, per kilo of product. } \\
\text { Fraction of products made of certified organically } \\
\text { grown cotton. }\end{array}$ \\
\hline Car & $\begin{array}{l}\text { Fuel consumption }(\mathrm{km} / \mathrm{l}) \\
\text { Emissions of NOx and particles }(\mathrm{g} / \mathrm{km}) \\
\text { Fraction of cars running on new hybrid systems }\end{array}$ \\
\hline
\end{tabular}

Source: Poll 2005 
step, it would be possible to weight together the 25 product groups according to production volumes in the European PRODCOM statistics (2). However, the translation of product groups of the Basket into PRODCOM codes is difficult, and in the end does presumably not provide much in return, due to lack of complete data sets for Europe.

We do not recommend aggregation of indicators into 25 product group indexes because such aggregation holds considerable uncertainties. In addition, as a policy monitoring tool, the specific information, available in the 69 indicators is valuable for understanding the development in each product group. At a later stage of IPP, if the concept has been developed further, aggregation may be relevant.

\section{Looking forward}

There is little data available for monitoring the Basket today. However, as IPP builds over the next decade, we expect more information on environmental aspects of products to be available, thus decreasing the cost of monitoring indicators in the Basket and making it a feasible approach.

Data should, to a large extent, be collected through agreements with European trade associations. Some legislation supports such co-operation, for example the WEEE Directive, and a future European Environmental Product Declaration (EPD sche$\mathrm{me}$ ). These will also generate valuable data for monitoring the progress of IPP through indicators. The EuP Directive sets requirements for manufacturers to document the environmental impact of their products. Thus, now, and over the next few years, is the time for developing a simplified methodology for life cycle screening. Such a development will be useful for LCA studies, EPD and eco-design and may lead to the creation of a very strong backbone in the IPP, if successful.

For the selection of the appropriate product groups, it is important to establish clear links to statistical product definitions, as well as to methodologies like the EIPRO project results; used to map environmental impacts from products in a systematic way (Tukker 2006). Such methodologies should be used in connection with the Basket of products, to provide a picture of the distribution of product groups in the Basket concerning environmental impact.

Eco-labelling criteria have been the main source for indicators selected for product groups. However, today eco-labelling bodies do not monitor their indicators. It is recommended that the eco-labelling society develops an approach where indicators are defined in each criteria document, and that license holders are obliged to report on these values on a regular basis.

In line with the perspectives of extracting indicators from the eco-labelling system, similar approaches may be relevant for greener public procurement and EMAS. If public calls for tenders contain environmental requirements to be met, then tenders will suddenly hold valuable information on environmental aspects of the products offered. For EMAS, introduction of mandatory reporting on selected parameters would give valuable data, and at the same time introduce benchmarking into the system.

Beside the quite specific recommendations, we see some areas of research. For example, on the level of supporting response indicators, we recommend increasing knowledge of organisational behaviour and adoption processes by business. From such knowledge, new supporting indicators should be developed. These could provide more precise information on the likely reaction of stakeholders to IPP measures. Another example of relevant research is ongoing development in the field of LCA methodology, input/output analysis, prioritisation studies and product impact indexes, which is crucial to a common European base for IPP. Finally, more knowledge on the possible roles of trade associations as turning points for information on products would be desirable.

If the European Commission chooses to carry on with the Basket of products as suggested, then the first step will be to plan a data acquisition strategy. After establishing a strategy, data acquisition may begin. The first round will establish a baseline for future reference. A first baseline of data has been given in the present study for some supporting indicators. During the first three to six years of monitoring, data sources should be assessed for quality, stability and coverage. The strategy may subsequently be adjusted, in order to give the best quality and reliability of data for the resources available.

\section{Remarks}

(1) Green Paper: COM [2001] 68. Communication: COM [2003] 302

(2) PRODCOM („List of PRODucts of the European COMmunity“) is the European classification scheme for product groups elaborated by Eurostat and available from RAMON, the Eurostat's Classification Server.

\section{Literature}

EEA, European Environmental Agency: Criteria for the selection of the EEA core set of indicators. Copenhagen w.y. (http://themes.eea.europa.eu/IMS/About/CSI-criteria.pdf)

Cadman, J. / Dolley, P.: The Direct and Indirect Benefits of the European Ecolabel. Copenhagen 2004. http://ec.europa.eu/environment/ecolabel/marketing/marketingstudies_en.htm)

Füssel, L.: Copenhagen Business School, telephone conversation. 2002.

Füssel, L.: Copenhagen Business School, telephone conversation. 2002.

Gabrielsen, P. / Bosch, P.: Environmental indicators: Typology and Use in Reporting. Copenhagen 2003.

Poll, C. / Vogt-Nielsen, K. / Rubik, F. / Jorgensen, M. / Jensen, M.: Development of Indicators for an Integrated Product Policy. EC - Final Report 2006. (http://ec.europa.eu/environment/ipp/ pdf/eu_incdicators_ipp_final_rep.pdf)

Tukker, A.: Environmental Impacts of Products (EIPRO). Seville 2006.

\section{AUTOREN + KONTAKT}

Christian Poll is head of section on Greener Products in the Danish Society for Nature Conservation.

Danmarks Naturfredningsforening, Masnedoegade 20, DK-2100 Copenhagen, Denmark. Tel.: +45/3917/4067, E-Mail: cpo@dn.dk

Dr. Frieder Rubik is head of the department „Ecological Product Policy" of IÖW in its office Heidelberg. IÖW, Office Heidelberg, Bergstrasse 7, 69120 Heidelberg, Germany. Tel.: +49/6221/649166,

E-Mail: frieder.rubik@ioew.de
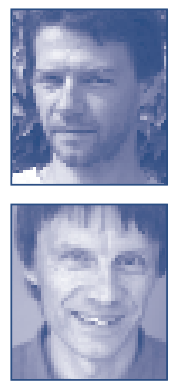
(c) 20I0 Authors; licensee IÖW and oekom verlag. This is an article distributed under the terms of the Creative Commons Attribution Non-Commercial No Derivates License (http://creativecommons.org/licenses/by-nc-nd/3.o/), which permits unrestricted use, distribution, and reproduction in any medium, provided the original work is properly cited. 